\title{
APPLICATION OF TAMARIND SEEDS BASED CHELATING RESIN IN EFFLUENT TREATMENT
}

\author{
Neha Parihar ${ }^{1}$, Kamini Sharma $^{2}$, Sawai Singh Rathore ${ }^{1}$ and Vikal Gupta ${ }^{1, \bowtie}$ \\ ${ }^{1}$ Department of Chemistry, Jai Narain Vyas University, Jodhpur-342005, Rajasthan, India \\ ${ }^{2}$ Department of Chemistry, Vivekananda Global University, Jaipur, Rajasthan, India \\ ${ }^{\square}$ Corresponding Author: vikal_chem@yahoo.co.in
}

\begin{abstract}
Chelating resin from naturally occurring polysaccharides like Tamarind Kernel Powder (TKP) has been synthesized. This TKP resin is highly selective, hydrophilic and biodegradable. Secondary amine derivative of tamarind kernel powder can be used as a metal ion exchanger and also as a scavenger for heavy metal ions from the effluent samples of metallurgical industries. A suitable and cost-effective method has been employed to reach the result of this experiment.

L-isoleucine acts as the backbone on the tamarind kernel powder in dioxane medium. The selective chelating resins and ion exchange resins have been used in the removal of harmful heavy metal ions from effluent samples of metallurgical and mineral industries.
\end{abstract}

Keywords: TKP (Tamarind Kernel Powder), L-isoleucine, Chelating Resin and Polysaccharide.

RASĀYANJ. Chem., Vol. 14, No.4, 2021

\section{INTRODUCTION}

It is a worldwide environmental concern that wastewater pollution caused by indiscriminate disposal contains toxic heavy metal ions. The poor treatment of waste products and wastewater from metal and metal finishing industries causes environmental damage and a serious hazard to all living organisms, human beings and animals.

Pollution due to heavy metals is a global problem; the toxicological effect of heavy metals, even in trace amounts, cause a severe health hazard to all forms of life. The accumulative nature of heavy metals in soft tissues in the human body caused many diseases, including Neuron logical damage, irritability, paralysis, blindness, liver and kidney damage, chronic asthma, disease, anemia, hepatitis, and nephritic syndrome. If these heavy metals enter a food chain at large concentration, they can hurt the human body.

A comprehensive list of methods like chemical precipitation, reduction, electrochemical precipitation, membrane separation, cementation, evaporation, foam separation, freeze separation, chemical coagulation, ion exchange, reverse osmosis, electro dialysis, solvent extraction, electroflotation and adsorption have been used to remove of heavy metals from wastewater.

Suitable and cost-effective methods have been used to reach the result of this experiment. The separation of many transition elements was done using ion exchange resins and chelating resins. Being costeffective, it is the effort of many resin manufacturers to produce a wide range of chelating ion exchange resins to encourage its application in ion exchange. Many naturally occurring adsorbents have low adsorbing power and lack availability. Heavy metals mainly occur in a natural mineral form such as sulfides, oxides, carbonates and silicates. ${ }^{1-4}$

The uptake of metals with the help of adsorbents has been attributed to biochemical constituents like proteins, lignin and carbohydrates. These may consist of many functional groups including carboxyl, hydroxyl and other amine derivatives that can be responsible for metal sorption.

Adsorption by natural polymers (tamarind or chitin) has become a popular technology process. Remediation of heavy metal ions and recovery of precious metals are essential processes of adsorption. These may consist of carboxyl, hydroxyl and other amine derivatives that can be responsible for metal sorption. Its advantages over conventional techniques are low cost, metal-selective, regenerative, no sludge generation, possible metal recovery, competitive preferences and high efficiency. This research 
focuses on synthesizing natural polymer-based resins and adsorbent based on agro-residue to develop a cost-effective technology for treating contaminated industrial wastewater. ${ }^{5-10}$

The present work describes the synthesis and application of ACMBHPE TKP resin to remove toxic metals like lead, cadmium, zinc, copper, iron, and nickel from various mineral and metallurgical industries. This work provides information about newer materials for the removal of heavy metals; simultaneously, it would help understand sorption, desorption and ion exchange of metal ions leading to a comparison with the conventional and reported materials.

\section{EXPERIMENTAL}

\section{Preparation of Secondary Amine Epoxide (ACMBHPE TKP Resin)}

The formation of secondary amine epoxide takes place when L-isoleucine reacts with epichlorohydrin. $\mathrm{NH}_{2}$ opens the epoxide ring by $\mathrm{SN}^{2}$ attack and compound (III) is formed, which on reaction with $\mathrm{NaOH}$ form secondary amine epoxide (IV).

0.1 mole of epichlorohydrin was taken in $250 \mathrm{ml}$ round bottom flask, which was fitted with a reflux condenser. 13.11 grams, i.e., 0.1 moles of L-isoleucine ( $40 \%$ solution in water), was added dropwise to it. The temperature was maintained at about $315 \mathrm{~K}$. Heat was evolved during the reaction, so cooling was necessary and the flask was equipped with a condenser to prevent the loss of L-isoleucine amino acid. About $20 \mathrm{ml}$ of $50 \%$ aqueous solution of sodium hydroxide $(0.1 \mathrm{~mole} \mathrm{NaOH})$ was added drop by drop to the above reaction mixture, using phenolphthalein as an indicator. Stirring was continued for 3 hours and then this solution was extracted using acetone 3 times in order to separate it from solid sodium chloride formed during the procedure. ${ }^{11-12}$

0.5 mole i.e., $83 \mathrm{~g}$ tamarind kernel powder was taken in dioxane and $5 \mathrm{ml}$ of $50 \%$ aqueous $\mathrm{NaOH}$ was added in order to make it alkaline. Secondary amine epoxide (IV) solution in dioxane medium was added to the alkalinetamarind kernel powder solution with constant stirring. This reaction was carried out for 4 hours. The resin 3- amino (1'- Carboxy, 2'- Methyl butyl) - 2 - hydroxy propyl ether of TKP i.e ACBHPE resin (product V) was obtained as shown in Scheme-1. This resin was filtered andfurther washed with 70\% methanol solution containinga small amount of acetic acid. After that, it was dried in the air.

\section{Treatment of Effluent}

Effluent samples were collected from mineral and metallurgical industries of the Jodhpur region. Further, these effluents samples were analyzed to know the concentration of heavy and toxic metals along with calcium, magnesium, sulphate ions. Characteristics and chemical composition of effluent samples from two units of mineral and metallurgical industries are reported in Table-1.

The column method was applied for the removal of metal ions from the new ACMBHPE resin of tamarind. In the column method diameter of the resin, bed was taken as one-tenth of the height of the column. A well-packed column was prepared by using TKP resin of a narrow size range. The ACMBHPE resin was stored with water for twenty minutes. Here fine particles were removed by decantation and the slurry of resin was transferred portion-wise to the column already filled with water. When the particular metal ion solution was loaded in the column, this newly polymer-bound chelating agent was present in the form of sodium. Later, it formed chelate and further, it released sodium ions. A colored band was formed when the solution traveled through this resin column, which was further eluted by perchloric acid solution. In the case of two or more metal ions, the band which formed a weaker complex will be released first. ${ }^{13-15}$

The eluate was collected in a volumetric flask and further subjected for the estimation of metal ions. The obtained results are reported in Table-2.

Table-1: Characteristics and Chemical Composition of Effluents from Two Metallurgical Industries

\begin{tabular}{c|c|c}
\hline & \multicolumn{2}{|c}{ Sources } \\
\hline $\begin{array}{c}\text { Chemical Composition and } \\
\text { Characteristics }\end{array}$ & $\begin{array}{c}\text { Effluent Sample } \\
\text { (Industry A) }\end{array}$ & $\begin{array}{c}\text { Effluent Sample } \\
\text { (Industry B) }\end{array}$ \\
\hline Colour & Brown & Light brown \\
\hline Total hardness(ppm) & 948 & 860 \\
\hline $\mathrm{pH}$ & 6.9 & 4.5 \\
\hline Calcium & 150 & 120 \\
\hline \multicolumn{2}{c}{2353} & Neha Parihar et al.
\end{tabular}


RASĀYAN J. Chem.

Vol. 14 | No. 4 |2352-2356| October- December | 2021

\begin{tabular}{c|c|c}
\hline & 46.04 & 80.21 \\
\hline Magnesium & 4.42 & 0.20 \\
\hline Zinc & 0.78 & 0.16 \\
\hline Lead & 714 & 660 \\
\hline Sulphate & 78 & 4.3 \\
\hline Iron & 0.75 & 1.89 \\
\hline Copper & 0.31 & 0.28 \\
\hline Fluoride & 0.45 & 0.80 \\
\hline Cadmium & &
\end{tabular}

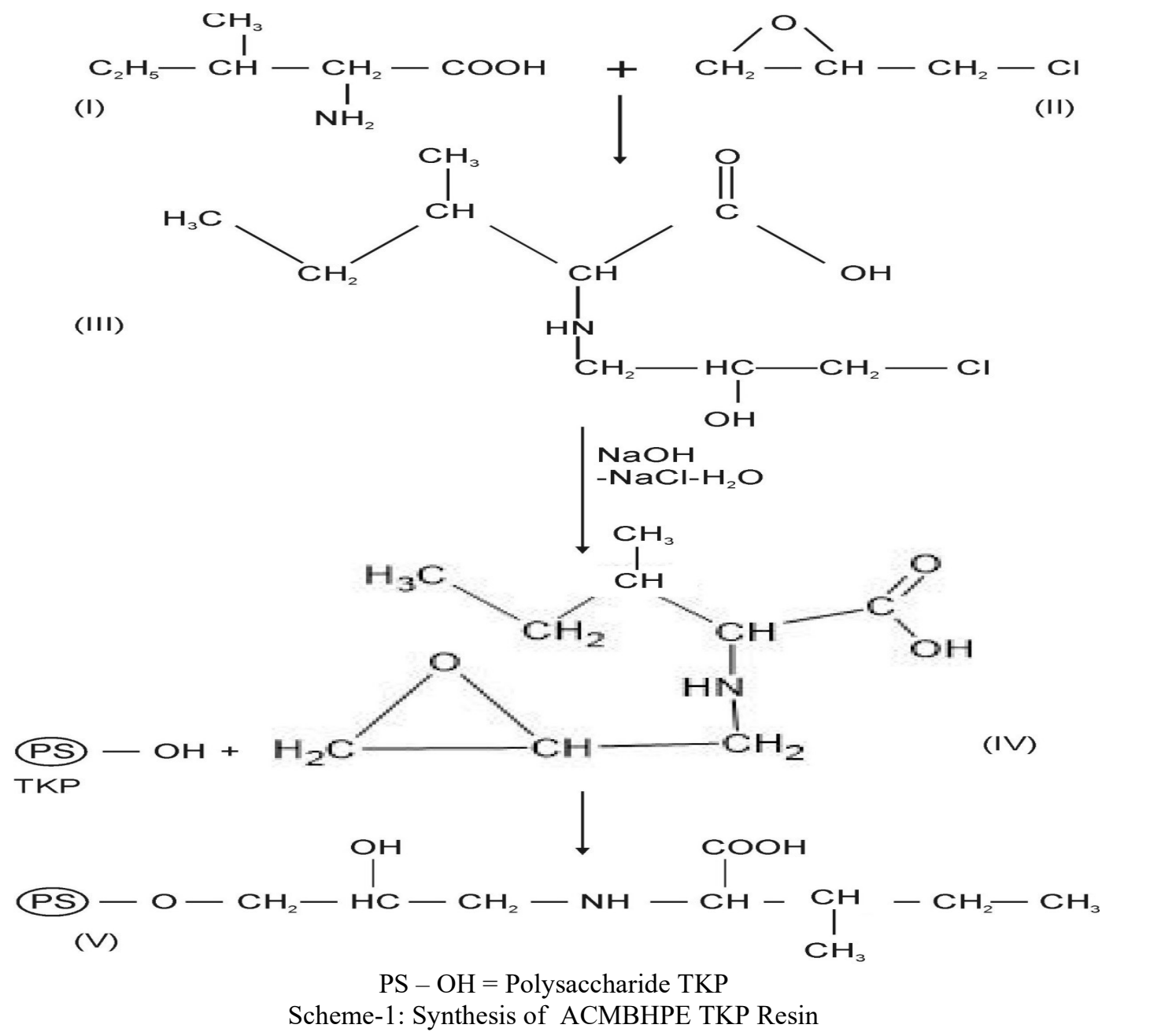

Table-2: Removal of Metal Ions From the Effluent Samples From Minerals and Metallurgical Industries

\begin{tabular}{|c|c|c|c|c|}
\hline & Metal Ions & $\begin{array}{l}\text { Conc. of Metal } \\
\text { Ions in } \\
\text { Untreated } \\
\text { Effluents }\end{array}$ & $\begin{array}{l}\text { Conc. of Metal Ions } \\
\text { after Treatment } \\
\text { with Lime } \\
\text { (pH 8.0) }\end{array}$ & $\begin{array}{l}\text { Conc. of Metal } \\
\text { Ions } \\
\text { after Treatment } \\
\text { with TKPResin } \\
\text { (at pH8.0) }\end{array}$ \\
\hline \multirow{7}{*}{$\begin{array}{l}\text { Effluents sample } \\
\text { of Industry (A) }\end{array}$} & Calcium & 150 & 150 & 149.4 \\
\hline & Magnesium & 46.04 & 46.04 & 46.01 \\
\hline & Zinc & 4.42 & 0.98 & 0.02 \\
\hline & Lead & 0.78 & 0.14 & Nil \\
\hline & Iron & 78 & 2.6 & Nil \\
\hline & Copper & 0.75 & 0.01 & Nil \\
\hline & Cadmium & 0.45 & 0.06 & Nil \\
\hline \multirow{2}{*}{$\begin{array}{l}\text { Effluent sample } \\
\text { of Industry (B) }\end{array}$} & Calcium & 120 & 120 & 119.5 \\
\hline & Magnesium & 80.21 & 80.21 & 80.01 \\
\hline
\end{tabular}


RASĀYAN J. Chem.

Vol. 14 | No. 4 |2352-2356| October-December | 2021

\begin{tabular}{l|c|c|c|c}
\hline & Zinc & 0.20 & 0.01 & Nil \\
\cline { 2 - 5 } & Lead & 0.16 & Nil & Nil \\
\cline { 2 - 5 } & Iron & 4.3 & 0.69 & Nil \\
\cline { 2 - 5 } & Copper & 1.89 & 0.15 & Nil \\
\cline { 2 - 5 } & Cadmium & 0.80 & 0.02 & Nil \\
\hline
\end{tabular}

RESULTS AND DISCUSSION

Industrial effluents are the main source of metal pollution. Industrial effluents are generated from various types of industrial processes. The effluent is mainly generated by metal processing and mineral industries. Heavy metal ions can be discharged into the natural stream in accordance with their tolerance limit which varies for different metals. Heavy and toxic metal ion concentrations can be brought to a degree of safety by applying the wastewater treatment technique. These observations have shown that the secondary amine derivative of TKP can be used to reduce heavy metal ions concentration in effluents to safer limits.

ACMBHPE TKP resin has been found successful in reducing the heavy metal ion concentration from industrial effluents to a level which was much lower than observed in the initial stage. Therefore, polymeric reagents can be considered very effective secondary treatment reagents. The greatest advantage of ACMBHPE TKP resin is its renewability. This can be regenerated by slightly altering the $\mathrm{pH} .{ }^{16-17}$

As shown in Table-2, calcium and magnesium metal ions cannot be removedduring the treatment of effluent samples with newly synthesized resin. The reason was the incomplete dissociation of salts of divalent calcium and magnesium in these effluent samples. The proposed structure of synthesized resin is well supported by IR \& 1 H NMR Data.

The newly synthesized tamarind resin i.e. ACMBHPE was characterized by FT-IR spectra as shown in Fig.-1. As reported in Table-3, the FT-IR spectra possess various peaks from which ACMBHPE resin can be analyzed. ${ }^{18}$

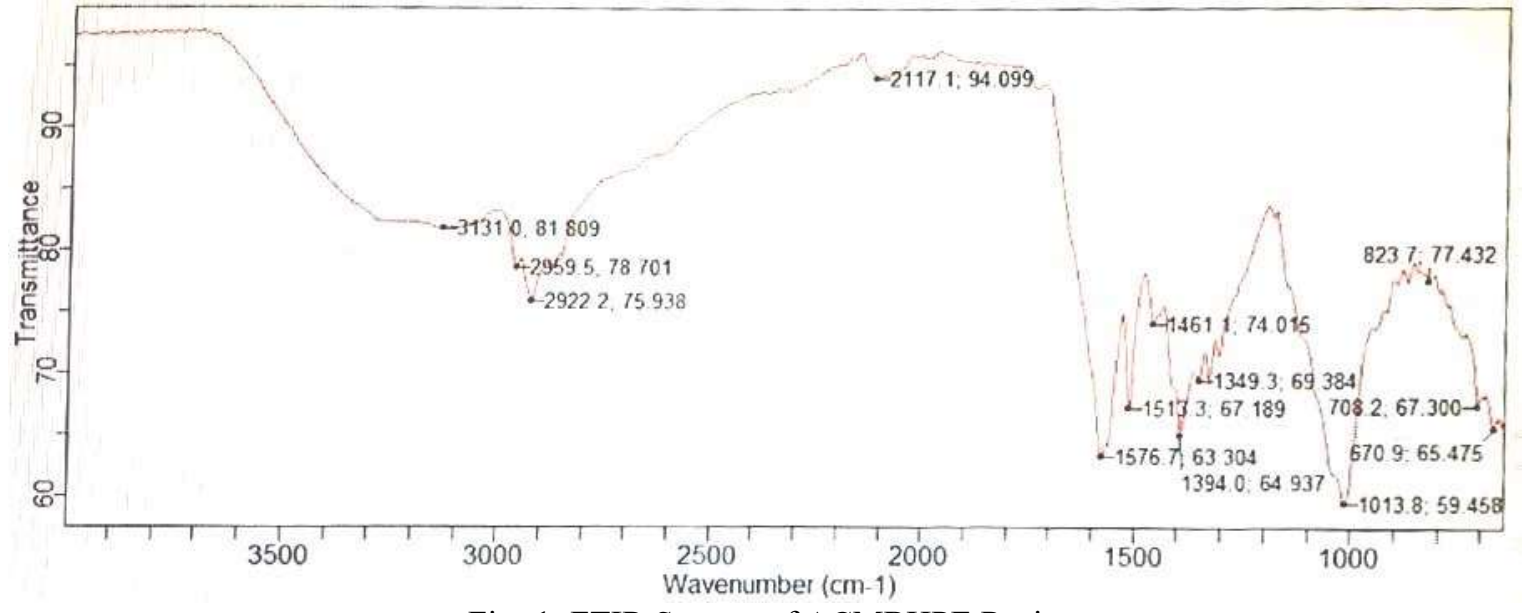

Fig.-1: FTIR Spectra of ACMBHPE Resin

These resins serve the purpose of both flocculants and ion binders. Preparation of resin includes polysaccharides, i.e., TKP, basically a flocculent and can be used on a large scale on a commercial basis. ${ }^{19}$ There is no limit to the quantity of water treated in one batch because reagents are directly added to the effluent. However, the conditions may change if the size of the resin bed and flow rate is factors.

Table-3

\begin{tabular}{c|c}
\hline Assignment & Frequency $\left(\right.$ in $\left.^{-1}\right)$ \\
\hline C-H Stretching & 2922.2 \\
\hline$-\mathrm{C}=\mathrm{O}$ Stretching & 1576 \\
\hline $\mathrm{CH}_{2}$ Stretching & 1461 \\
\hline O-H Stretching(in chelate form) & 2959 \\
\hline N-H Stretching & 3131 \\
\hline
\end{tabular}


RASĀYAN J. Chem.

Vol. 14 | No. 4 |2352-2356| October- December | 2021

\section{CONCLUSION}

The result of this study reveals that the metal ion uptake by newly synthesized chelating resin is successful \& rapid. The effect of the pH is not prominent. The FT-IR of the new TKP resin indicates that the tamarind-based chelating resin has functional groups, which facilitate the adsorption of heavy metal by mainly chelating,ion exchange and cross-linking.

\section{ACKNOWLEDGEMENT}

The authors are thankful and grateful to HOD, Chemistry Department, Jai Narain Vyas University, Jodhpur, for providing instruments and laboratory facilities.

\section{REFERENCES}

1. M. Ajmal, A. H. Khan, S. Ahmad and A. Ahmad, Water Research, 32(10), 3085(1998), https://doi.org/10.1016/S0043-1354(98)00067-0

2. M. Dakiky, M. Khamis, A. Manassra and M.Mereb, Advances in Environmental Research, 6(4), 533(2002), https://doi.org/10.1016/S1093-0191(01)00079-X

3. C.A. Kozlowski and W. Walkowiak, Water Research, 36, 4870(2002), https://doi.org/10.1016/S00431354(02)00216-6

4. V. J. Inglezakis, M. M. Loizidou and H. P. Grigoropoulou, Journal of Colloid and Interface Science, 275(2),570(2004), https://doi.org/10.1016/j.jcis.2004.02.070

5. C. Morisseau and B. D. Hammock, Annual Review of Pnarmacology and Toxicology,45, 311(2005), https://doi.org/10.1146/annurev.pharmtox.45.120403.095920

6. Hopmann, Kathrin, Himo and Fahmi, Chemistry - A European Journal,12(26), 6898(2006), https://doi.org/10.1002/chem.200501519

7. P. Siddhuraju, Journal of Food Science and Technology, 40(6), 982(2007), https://doi.org/10.1016/j.1wt.2006.07.010

8. M. Uysal and A. Irfan, Journal of Hazardous Materials, 149(2), 482(2007), https://doi.org/10.1016/j.jhazmat.2007.04.019

9. H. Patel and R. T. Vashi, Journal of Chemistry,7, 987620(2010), https://doi.org/10.1155/2010/987620

10. V. Srivastava, C.H. Weng, V.K. Singh, Y. C. Sharma, Journal of Chemical \& Engineering Data, 56(4), 1414(2011), https://doi.org/10.1021/je101152b

11. S. Deng, P. Wang and Y. Dou, Journal of Hazardous Materials, 307, 64(2016), https://doi.org/10.1016/j.jhazmat.2016.01.002

12. P. Ajitha , K. Vijayalakshmi , M. Saranya , T. Gomathi , K. Rani and P.N. Sudha, International $\begin{array}{lllll}\text { Journal of Biological } & \text { Macromolecules, } & \text { 104, }\end{array}$ https://doi.org/10.1016/j.ijbiomac.2017.05.111

13. F. Zhou, X. Feng, J. Yu and X. Jiang, Environmental Science and Pollution Research, 25, 15651(2018), https://doi.org/10.1007/s11356-018-1733-8

14. I. B. Surati and F. P. Minocheherhomji, International Journal of Chemistry, 2320(2018), http://dx.doi.org/10.21474/IJAR01/6647

15. V. Gupta, Nisha and M. Choudhary, Journal of Pharmacognosy and Phytochemistry, 8(3),107(2019).

16. M. Lebedevaite, J. Ostrauskaite, E. Skliutas and M. Malinauskas, Journal of Applied Polymer Science, 10, 9758(2020), https://doi.org/10.1038/s41598-020-66618-1

17. A. V. Singh and I. K. Kumawat, Water SA South Africans Water Research Commission ,38(4) (2012), https://doi.org/10.4314/wsa.v38i4.7

18. N. K. Sharma and A.V. Singh, Environmental Toxicology and Chemistry,93(10), 1897(2010), https://doi.org/10.1080/02772248.2011.626414

19. D. K. Soni, A. V. Singh and I. K. Kumawat, Water and Environment Journal, 26(3), 371(2011), https://doi.org/10.1111/j.1747-6593.2011.00297.x

[RJC-6528/2021] 